Fecha de recepción: marzo 2021 Fecha de aceptación: abril 2021 Versión final: mayo 2021

\section{Entre tecnologia e nostalgia: a fotografia analógica revisitada pelo design}

Laís Akemi Margadona ${ }^{(1)}$, Fernanda Henriques ${ }^{(2)}$ y

Ana Beatriz Pereira de Andrade ${ }^{(3)}$

Resumo: Nota-se na contemporaneidade práticas projetuais voltadas para processos manuais, analógicos, e por que não, nostálgicos. Neste panorama, “\#savethefilm” é resultado de uma pesquisa-ação em fotografia analógica em projetos de Design. Propõe um diálogo interdisciplinar entre metodologias artesanais e digitais a partir de três grandes áreas a saber: Fotografia, Design Gráfico e Design Digital. Em termos metodológicos, as referências contemplam o hibridismo no Design contemporâneo relacionado aos processos fotográficos. Foram desenvolvidas experimentações visuais que validaram as possibilidades de intercâmbio entre plataformas e áreas de conhecimento. A pesquisa aplicada apresenta resultados práticos híbridos, transpostos para ambientes digitais. O objetivo final foi delinear premissas criativas e projetuais para produções que evoquem a nostalgia e o colecionismo.

Palavras-chave: Design - Design Gráfico - Fotografia Analógica - Processos Artesanais.

[Resumos em espanhol e inglês nas página 130]

(1) Laís Akemi Margadona. Doutoranda em Comunicação pela Universidade Estadual Paulista "Júlio de Mesquita Filho" (UNESP, Brasil), Mestre em Mídia e Tecnologia (UNESP, Brasil) e Bacharel em Design - Habilitação em Design Gráfico (UNESP, Brasil). Professora bolsista no Departamento de Design (FAAC/UNESP, Brasil). Membro do GENEM - Grupo de Estudo em Nova Ecologia dos Meios (CNPq/UNESP). e-mail: lais.akemi@unesp.br.

(2) Fernanda Henriques. Doutora e mestre em Comunicação e Semiótica pela Pontifícia Universidade Católica de São Paulo (PUC, Brasil). Bacharel em Publicidade e Propaganda pela Universidade Presbiteriana Mackenzie (Brasil). É líder do Grupo de Pesquisa Design Gráfico Inclusivo: audição, visão e linguagens (parceria entre a UNESP e a USP). Diretora da Faculdade de Arquitetura, Artes, Comunicação e Design (FAAC/UNESP). e-mail: fernanda. henriques@unesp.br.

(3) Ana Beatriz Pereira de Andrade. Doutora em Psicologia Social pela Universidade do Estado do Rio de Janeiro (UERJ, Brasil). Mestre em Comunicação e Cultura pela Universidade Federal do Rio de Janeiro (UFRJ, Brasil) e Bacharel em Comunicação Visual pela Pontifícia 
Universidade Católica do Rio de Janeiro (PUC-Rio, Brasil). Professora assistente doutora no Departamento de Design da FAAC/UNESP. Recebeu os títulos honoríficos de Miembro del Comité de Honor del Diseño Latinoamericano e de Embajador del Diseño Latino. e-mail: ana.b.andrade@unesp.br.

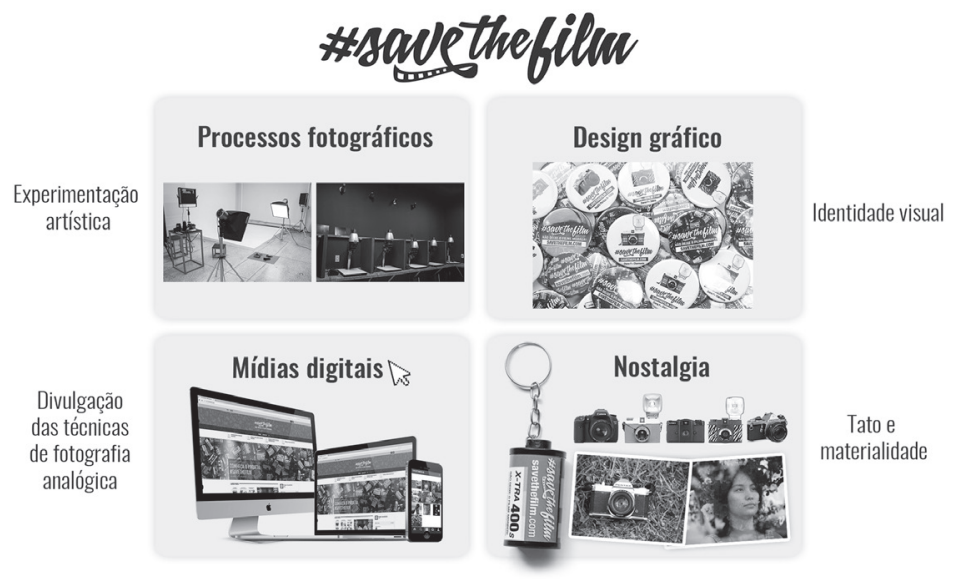

\section{Tecnologia e nostalgia}

Considerando a modernização dos sistemas visuais, percebe-se movimento na direção de práticas metodológicas mais lentas, contemplativas, artesanais. Desta forma, talvez, haja tendênciano sentido de capitanearjovens fotógrafos e designers. Alguns, se deleitam à experimentação estética para além do que de uma suposta perfeita reprodução. São os"nascidos em tempos líquidos" - os millenials e a geração X (Bauman\& Leoncini, 2018, p.17).

Em nostalgia, Svetlana Boym define as tensões que envolvem o termo: de patologia física à doença de uma imaginação aflita ${ }^{1}$ (Boym, 2001, p.4). Zygmunt Bauman (2017) cunha o termo "retrotopia", autopia do passado. Ou seja, nostalgia e pertencimento junto à memória coletiva.

Apresenta-seresultados sob forma de produtos desenvolvidos. A produção valida o hibridizar de diferentes ações analógicas e digitais. As ações transitam entre a tecnologia dos softwares e a nostalgia da materialidade impressa. 


\section{Apresentando o projeto}

\#savethefilm foi idealizadocomo uma iniciativa autoral acerca dafotografia analógica. Apesquisa-ação partiu do princípio de realizar práticas, aplicando caráter qualitativo e exploratório.O ponto de partida foi o de inspirar jovens fotógrafos, designers e artistas interessadosno universo artesanal a resgatarem e experimentarem técnicas.

Devido à voracidade do capitalismo que rege o mercado de equipamentos digitais, "\#savethefilm” faz alusão à possibilidade de uso do filme fotográfico ser considerado obsoleto.

O título da pesquisa é precedido de uma hashtag, “\#”, palavra-chave indexável em mecanismos de busca em mídias sociais. Tal escolha que enfatiza odiálogo colaborativo entre digital e artesanal, propondo reflexões.

\section{Reflexões}

Quais as possibilidades plásticas, estéticas e de produção de sentido que a fotografia analógica proporciona?

De que forma as imagens podem ser aplicadas em design gráfico, revelando diálogos interdisciplinares?

Como conjugaras linguagens digitais e artesanais a fim de propor a possibilidade de comunhão entre tecnologia e nostalgia?

\section{Trajetórias}

A pesquisa-ação afirma que "o pesquisador e os representantes da pesquisa estão mutuamente envolvidos" e "supõe uma investigação planejada em caráter educacional ou social" (Alves, 2007, p.57). Tais premissas coincidem com os objetivos de partilhar conhecimento. O cronograma da pesquisa foi executado conforme as seguintes etapas:

1. Revisão bibliográfica em design gráfico contemporâneo, fotografia e processos artesanais;

2. Delimitação da proposta do projeto \#savethefilm;

3. Elaboração de identidade visual considerando as plataformas digital e impressa;

4. Produção fotográfica analógica utilizando a estrutura do Laboratório de Fotografia da 5. FAAC/UNESP e laboratórios terceirizados na cidade de Bauru (SP, Brasil) e Ibitinga (SP, Brasil);

6. Produção fotográfica digital utilizando a estrutura do estúdio do Laboratório de Fotografia da FAAC/UNESP;

7. Criação de peças gráficas impressas;

8. Criação do layout, hospedagem e implementação do website;

9. Criação das páginas nas mídias sociais Facebook e Instagram, e

10. Entrevistas com fotógrafos, designers e pesquisadores relacionados ao contexto desta pesquisa. 


\section{Identidade}

Os conceitos para a concepção da marca foram: legibilidade, elementos da caligrafia manuale desenho contemporâneo. Na construção tipográfica, a descendente na letra "e" de "save" remete simbolicamente aos quadros da emulsão da película fotográfica.

\section{* save the fillur}

Figura 1. Marca do projeto

\#savethefilm. Fonte: Acervo pessoal.

\section{Fotografias}

As fotografias foram produzidas para uso no projeto gráfico impresso e digital. Podem ser trabalhadas como malhas ou planos de fundos das peças gráficas.

Dentre as imagens digitais, foram capturados equipamentos como bobinas de filme e câmeras antigas. $\mathrm{O}$ intuito foi o de despertar a curiosidade de fotógrafos iniciantes e nostalgia naqueles que já trabalharam com a plataforma.
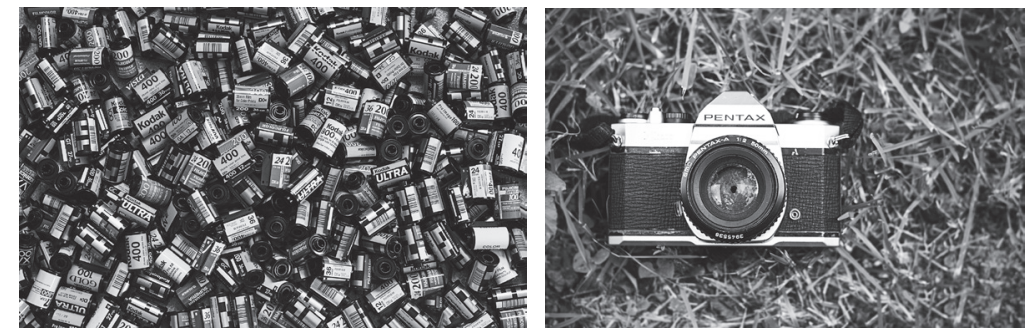

Figuras 2 e 3. Fotografias digitais retratando equipamentos analógicos.

Fonte: Acervo pessoal. Equipamento de captura: Canon EOS 3 e 50mm f/1.8 II.

\section{Produtos}

O projeto gráfico buscou inspiração na estética retrô, entendida como "um aspecto do pós-modernismo, devido ao seu interesse pelas retomadas históricas" (Meggs \& Purvis, 2009, p.616). Na obra "Design retrô: 100 anos de design gráfico", Raimes \& Bhaskaran (2007) afirmam que "o passado é uma fonte de inspiração em nossa busca constante pela originalidade” (Raimes \& Bhaskaran, 2007, p.6).

Foi percebida a possibilidade de explorar o potencial simbólico do rolo de filme, um ícone afetivoda fotografia analógica. As bobinas plásticas seriam originalmente descartadas por 
laboratórios fotográficos. Cinco artes buscam emular os rótulos de filmes clássicos das marcas Kodak e Fujifilm.

Um livro foi desenvolvido narrando o memorial do projeto. Sua versão impressa foi desenvolvida e a versão digital está disponível integralmente na plataforma de portfolios Behance ${ }^{2}$.
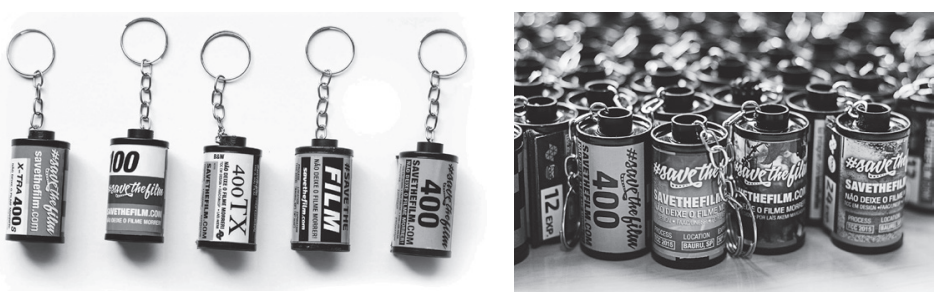

Figuras 4 e 5. Chaveiros de bobina de filme. Fonte: Acervo pessoal.
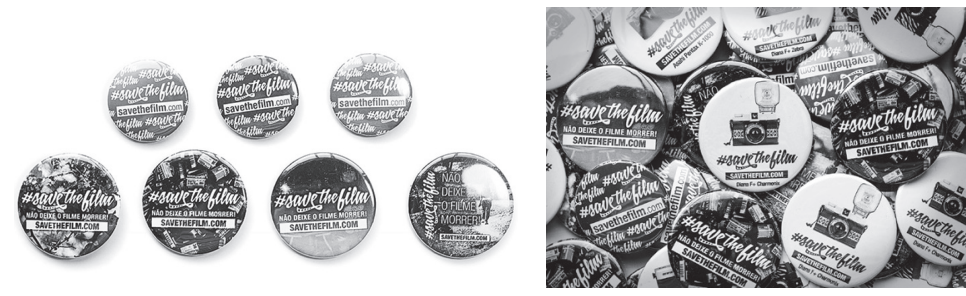

Figuras 6 e 7. Broches impressos em dimensões 3,5 e 4,5cm. Fonte: Acervo pessoal.
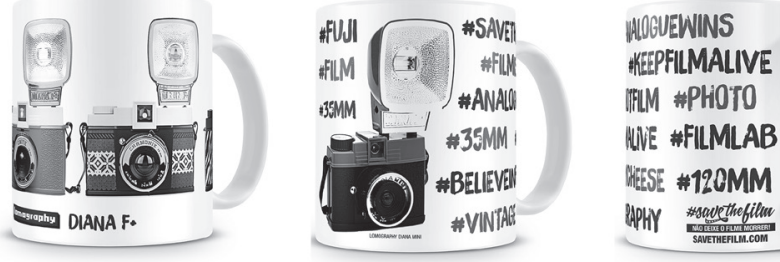

Figura 8. Mockup de caneca com a identidade \#savethefilm. Fonte: Acervo pessoal.
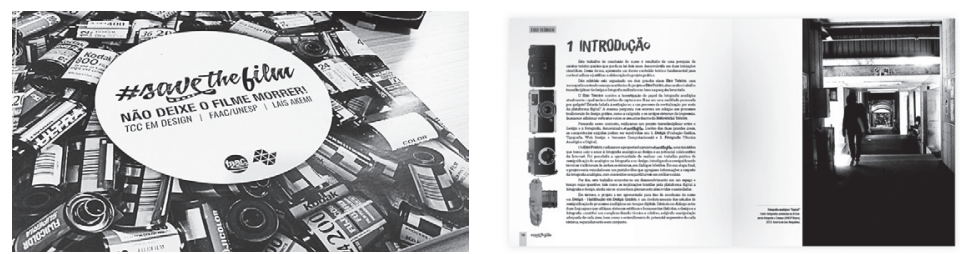

Figuras 9 e 10. Memorial do projeto em formato de livro. Fonte: Acervo pessoal. 


\section{Design digital}

A metodologia de criação consistiu em pesquisa de layouts, preparação do servidor para hospedagem e instalação da plataforma Wordpress. O protótipo do website é responsivo para diferentes tamanhos de tela.

Os perfis nas mídias Instagram e Facebook foram projetados para gerar engajamento. No projeto original, o Instagram é dedicado a realizar a curadoria de imagens enviadas por fotógrafos do círculo independente.

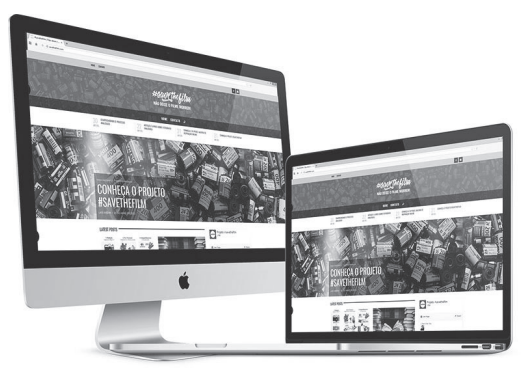

Figura 11. Visão do website em monitor dedicado e notebook. Fonte: Acervo pessoal.
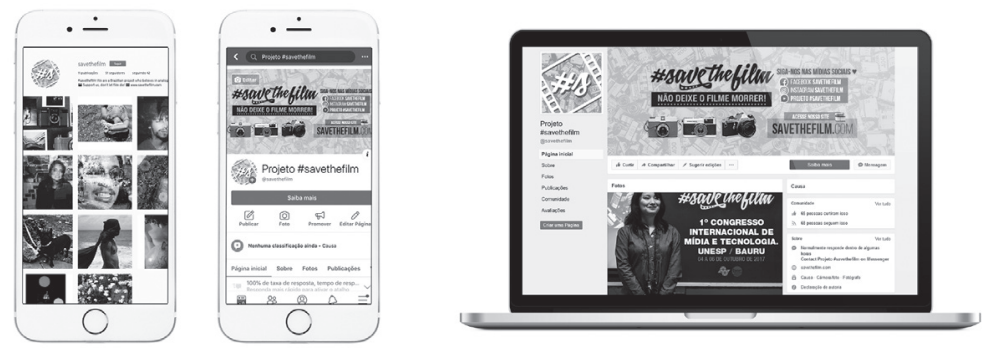

Figuras 12 e 13. Visão das mídias sociais Facebook e Instagram (versões web e desktop). Fonte: Acervo pessoal.

\section{Analógicos x digitais: uma batalha sem vencedores}

Considerando que os sistemas automatizados alteram a dinâmica e a relação com as ações criativas, verifica-se que a cada tecnologia desenvolvida, resultados plásticos diferentes também surgem. Novos recursos abrem novos caminhos, assim como impõem limites que precisam ser testados. 
O resgate de técnicas artesanais não confina os elementos antigos aos ambientes primitivos. São hibridizados com as novas tecnologias, promovendo amplitude em resultados gráficos. A linguagem gerada desses cruzamentos tende a produzir proximidade do produto com o público ao evocar a nostalgia e um senso de comunidade.

Como resultado, a pesquisa-ação aplicada em design e fotografia trata de dialogar com intersecções entre plataformas, estéticas e temporalidades. Éum desdobramento prático dos estudos de ressignificação de processos analógicos em tempos digitais.

\section{Agradecimentos}

A pesquisa foi parcialmente desenvolvida no Laboratório de Fotografia da Faculdade de Arquitetura, Artes, Comunicação e Design (FAAC/UNESP) e financia da pela PróReitoria de Pesquisa (PROPe/UNESP).

\section{Notas}

1. Do original, "Nostalgia, the disease of an afflicted imagination" (Boym, 2001, p.4).

2. Recuperado de: https://www.behance.net/gallery/68925977/Projeto-savethefilm

\section{Referências}

Alves, M. (2007). Como escrever teses e monografias. Rio de Janeiro: Elsevier.

Bauman, Z. (2017). Retrotopia. Rio de Janeiro: Zahar.

Bauman, Z., \& Leoncini, T. (2017). Nascidos em tempos líquidos: transformações no terceiro milênio. 1. ed. Rio de Janeiro: Zahar.

Boym, S. (2001). The future of nostalgia. Basic Books, Nova Iorque.

Lomography. (2012). Lomo Life - The Future is Analog: The Story. Londres: Thames \& Hudson.

Martins, N. (2014). Fotografia: da analógica à digital. Rio de Janeiro: Senac Nacional.

Meggs, P., \&Purvis, P. (2009). História do Design gráfico. São Paulo: Cosac Naify.

Monforte, L. G. (1997).Fotografia pensante. São Paulo: Editora Senac São Paulo.

Nojima, V. L., Braida, F., \& Moura, M. (2014). A contemporaneidade híbrida nas Artes e no Design. In: M. Moura (Org.). Design brasileiro contemporâneo: Reflexões (Cap. 69, pp. 69-92). São Paulo: Estação das Letras e Cores.

Raimes, J., \&Bhaskaran, L. (2007). Design retrô: 100 anos de Design gráfico. São Paulo: Editora Senac São Paulo.

Rocha, C. (2011). Materialidade digital. In G. B. Campos \& M. Ledesma (Org.). Novas Fronteiras do Design Gráfico (Cap. 11, pp. 151-157). São Paulo: Estação das Letras e Cores. 
Schisler, M. W. L. (1995).Revelação em preto-e-branco: a imagem com qualidade. São Paulo: Martins Fontes.

Wheeler, A. (2012). Design de identidade da marca: guia essencial para toda a equipe de gestão de marcas. 3 ed. Porto Alegre: Bookman.

Resumen: Todavía se ven en el diseño contemporáneo prácticas centradas en procesos manuales, analógicos y, por qué no, nostálgicos. En este escenario, "\#savethefilm” es el resultado de una investigación-acción en fotografía analógica en proyectos de diseño. Propone un diálogo interdisciplinario entre metodologías artesanales y digitales desde tres áreas principales: Fotografía, Diseño Gráfico y Diseño Digital. En términos metodológicos, las referencias incluyen el hibridismo en el diseño contemporáneo relacionado con los procesos fotográficos. Se desarrollaron experimentos visuales para validar las posibilidades de intercambio entre plataformas y áreas de conocimiento. La investigación aplicada presenta resultados prácticos híbridos, trasladados a entornos digitales. El objetivo final fue perfilar premisas creativas y proyectuales a producciones visuales que evocan la nostalgia y el coleccionismo.

Palabras clave: Diseño - Diseño Gráfico - Fotografía Analógica - Procesos Artesanales.

Abstract: Some contemporary Design practices are focused on analog, manual and, why not, nostalgic processes. In this scenery, "\#savethefilm" is an action research about analog photography applied to Design projects. It proposes an interdisciplinary dialog between artisanal and digital methodologies. Three main areas were involved: photography, graphic Design and digital Design. In methodological terms, the references include hybridism in contemporary Design related to photographic processes. Visual experiments validated the possibilities of exchange between platforms and fields of knowledge. The applied research presents practical hybrid results transposed to digital environments. Thus, we intended to outline creative and Design premises that evoke nostalgia.

Keywords: Design - Graphic Design - Analog Photography - Artisanal Processes.

[Las traducciones de los abstracts fueron supervisadas por el autor de cada artículo] 